\title{
Economic Value of Using CrWN Films and the Contribution of Using Control Chart for Process Stability
}

\author{
Shih-Hung TAI \\ Department of Industrial Management, \\ Lunghwa University of Science \& Technology \\ Taiwan \\ E-mail: tai3662@mail.lhu.edu.tw
}

\author{
Chun-Yao HSU \\ Department of Mechanical Engineering, \\ Lunghwa University of Science \& Technology \\ Taiwan \\ E-mail: cyhsu@ mail.lhu.edu.tw
}

\author{
I-Shin $\mathrm{CHEN}^{*}$ \\ Department of Business Administration, \\ Lunghwa University of Science \& Technology \\ Taiwan \\ E-mail: sinchen0105@gmail.com \\ +* Corresponding author
}

\begin{abstract}
This study investigates the optimization of direct current reactive co-sputter deposition process parameters to achieve multiple performance characteristics (roughness, roundness, and flank wear) in the CrWN thin films by the Grey-Taguchi method. In the confirmation runs, when using grey relational analysis, improvement of $17.045 \%$ was obtained in surface roughness, $20.833 \%$ in roundness, and $\mathbf{2 8 . 3 5 4 \%}$ in flank wear, respectively. Furthermore, control charts tell us when special causes of variation are impacting the direct current reactive co-sputter deposition process and product characteristics are stable over time.
\end{abstract} charts

Keywords-CrWN;co-sputter; grey-taguchi method; control

\section{INTRODUCTION}

Chromium tungsten nitride (CrWN) thin films were deposited onto tungsten carbide tools substrates, by direct current (DC) reactive magnetron co-sputter at room temperature. The effect and optimization of CrWN thin films deposition parameters (DC reactive magnetron co-sputter parameters: $\mathrm{Cr}$ power, $\mathrm{W}$ power, $\mathrm{N} 2 /(\mathrm{Ar}+\mathrm{N} 2)$ flow-rate ratios and deposition time) on the structure, roundness and flank wear in the turning operations were studied. To strengthen wear resistance in conventional tool materials, sputtering techniques (physical vapour deposition, PVD) have recently found increasingly wider use in such coating applications [1-3]. The morphological and properties of tool are the results of the effect of deposition parameters on the thin films (sputter power, substrate temperature, substrate rotate speed, substrate-to-target distance, base pressure and process pressure) [4-6]. In this study, the co-sputter process parameters (Cr DC power, W DC power, N2/( $\mathrm{Ar}+\mathrm{N} 2)$ flowrate ratios, and deposition time) were controlled to insert hard metal chromium tungsten nitride $(\mathrm{CrWN})$ onto tungsten carbide tools for dry machining. Taguchi experimental design is a powerful approach for increasing experimental efficiency. An L9 mixed orthogonal table in the Taguchi quality design derives important coating factors [7].Basically, experimental design methods were developed by Montgomery [8]. However, classical experimental design methods are too complex and not easy to use. Furthermore, a large number of experiments have to be carried out when the number of the process parameters increases. To optimize the process based on the experimental data, the traditional statistical regression requires a large amount of data, causes the difficulty in treating the typical normal distribution of data and the lack of variant factors.

In 1982, grey analysis was first proposed by Dr. Deng to fulfill the crucial mathematical criteria for dealing with poor, incomplete, and uncertain systems. In grey system theory, grey relational analysis is a measurement method to analyze the relationship between sequences using less data and multiple factors, and is considered more helpful to statistical regression analysis. Grey analysis can effectively recommend a method of optimizing the complicated interrelationships among multiple performance characteristics [9].

In this study, the DC reactive magnetron co-sputter process parameters of CrWN deposited on tungsten carbide tools were designed through Taguchi experimental design and grey relational analysis for turning performance. An important objective of statistical process monitoring and control is the fast detection of variation in the production system to enable necessary corrective actions to be taken before even more defective items are produced. Control charts tell us when special causes of variation are impacting machining process. Control charts are basic and powerful tools in statistical process control and are widely used to control various industrial processes. Advanced process monitoring techniques, such as exponentially weighted moving average, cumulative sum control charts, can be used in automated. 


\section{EXPERIMENTAL PROCEDURES}

The composite CrWN coatings were fabricated onto tungsten carbide tools using a dual gun sputtering apparatus with pure $\mathrm{Cr}$ and $\mathrm{W}$ metal targets. The $\mathrm{DC}$ reactive cosputtering of $\mathrm{Cr}$ and $\mathrm{W}$, and the sequential sputtering of the $\mathrm{Cr}$ and $\mathrm{W}$ with $\mathrm{N} 2$ gas inlet, were performed for $\mathrm{CrWN}$ coatings. Taguchi experimental design and grey relational analysis were also used to clarify the effect of the various cosputtering factors, aiming to obtain good surface finish, precise roundness, and small flank wear of the cutting tool. An L9 (34) orthogonal array with four columns and nine rows was introduced to govern the co-sputter process experiments. Table I shows the setting of factors and levels in co-sputter deposition conditions to form $\mathrm{CrWN}$ films. Using the Taguchi experimental design, the $\mathrm{S} / \mathrm{N}$ ratio analysis, statistical analysis of variance, and grey relational analysis, this work aims to find the optimal sputtering process parameters. Grey relational analysis can be used to solve complicated inter-relationships among multiple performance characteristics.

The grey relational grade is a weighted-sum of the grey relational coefficient. The grey relational grade shows the correlation between the reference sequence and the comparability sequence to be compared to. The evaluated grey relational grade fluctuates from 0 to 1 , and equals 1 if these two sequences are identically coincident. With grey relational analysis and statistical analysis of variance (ANOVA), the ideal combination of cutting parameters can be predicted.

\section{RESULTS AND DISCUSSION}

CrWN thin films have thickness of $55 \sim 190 \mathrm{~nm}$ with smooth surface and a good adhesion were deposited on tungsten carbide tools by dual gun DC reactive co-sputtering using pure $\mathrm{Cr}$ and $\mathrm{W}$ metal targets, at base pressure of $5.0 \times$ 10-6 torr (co-sputter deposition conditions to form different CrWN films shows in Table I).

After constructing the $\mathrm{S} / \mathrm{N}$ response table, an analysis of variance (ANOVA) table can be established based on the sum of the squares, the degree of freedom, and the mean square. The ANOVA results for roughness, roundness, and flank wear are listed in Table II. It is found the N2/ (Ar+N2) flow-rate ratio is the dominant flank wear effect of the cutting tool, having about a $42 \%$ contribution ratio. Additionally, $\mathrm{Cr}$ power also influences flank wear, having about a $33.3 \%$ contribution ratio.

The confirmed experiment results for the multiple performance characteristics of CrWN films are shown in Table III. A comparison of grey theory prediction design with the orthogonal array parameters indicates the surface roughness of the machined workpiece decreased from 0.88 to $0.73 \mu \mathrm{m}$, roundness decreased from 1.2 to $0.95 \mu \mathrm{m}$, and the flank wear of the cutting tool decreased from 39.5 to $28.3 \mu \mathrm{m}$, with improvement of $17.045 \%, 20.833 \%$, and $28.354 \%$, respectively.

Control charts are basic and powerful tools in statistical process control and are widely used to control various industrial processes. Fig. 1-3 show this set of three control charts as generated by Minitab. The Minitab package generates these charts automatically, referring to the individuals chart exhibits control and stable.

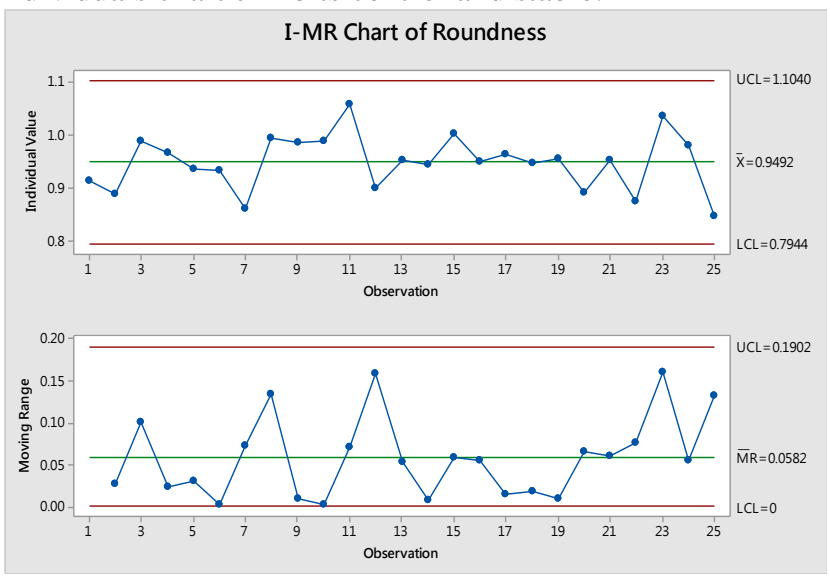

Figure 1. Roundness of the control chart for individuals and the moving range

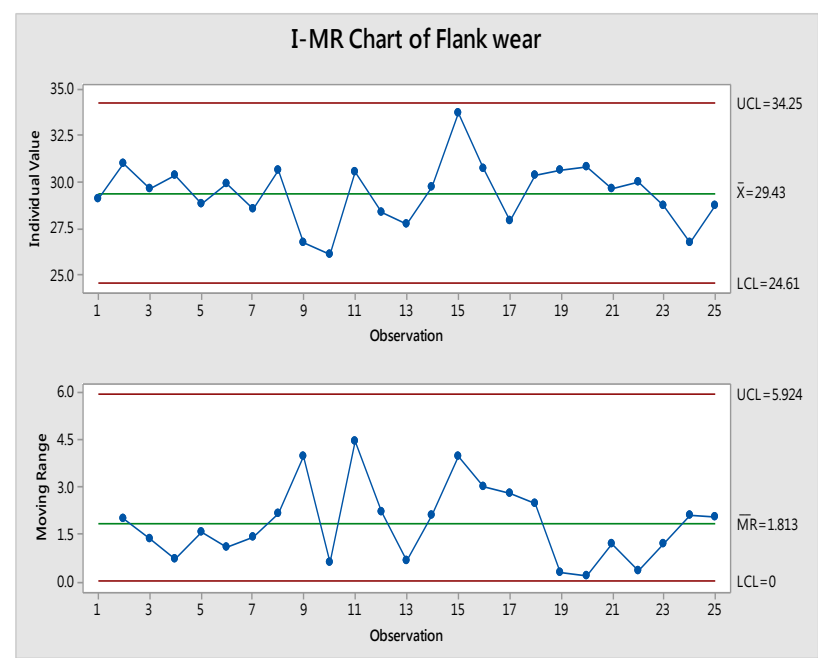

Figure 2. Flank wear of the control chart for individuals and the moving range

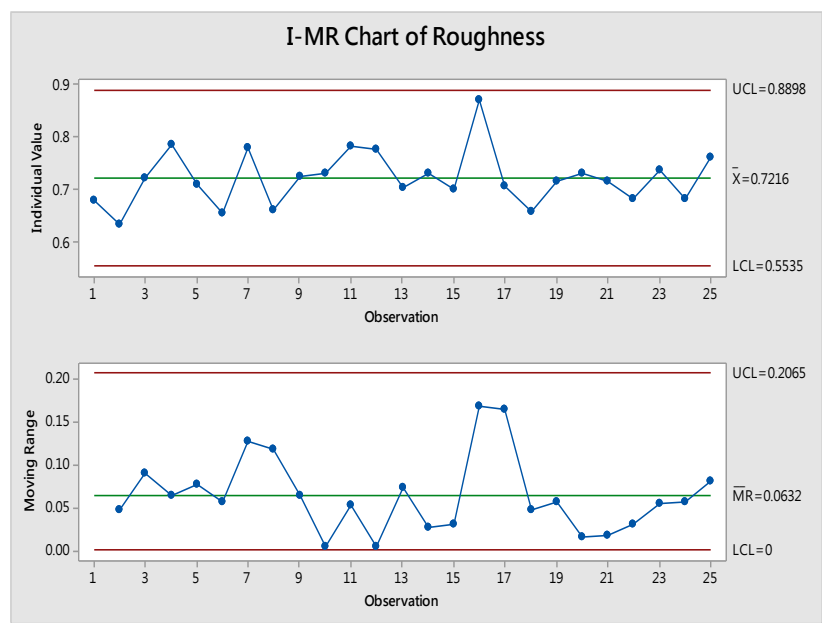

Figure 3. Roughness of the control chart for individuals and the moving range 
Repeat measurements on the process differ only because of laboratory or analysis error, as in many chemical processes. In such situations, the control chart for individual units is useful [10]. The aim of statistical process control is to explore the predictability of a process. Original idea, from Dr. Shewhart, when there are twenty-five subgroups, that is 25 individual measured items or data points, all in control.

It is important to check the normality assumption when using the control chart for individuals. A simple way to do this is with the normal probability plot. Fig. 4-6 is the normal probability plot from Minitab for the data. There is no obvious problem with the normality assumption.

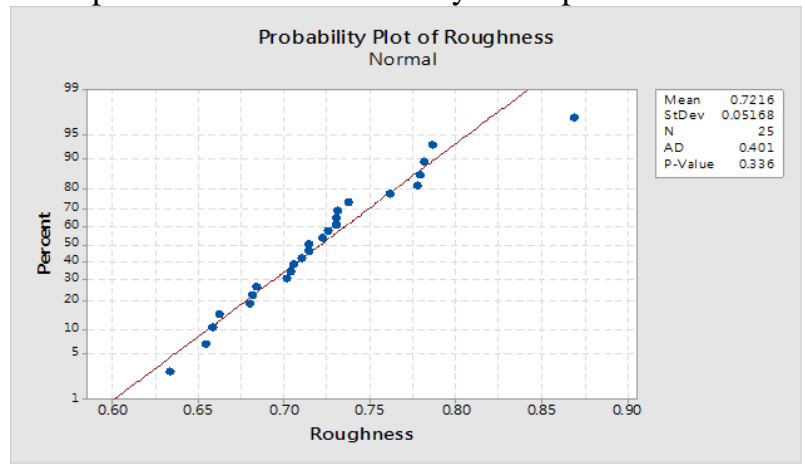

Figure 4. Normal probability plot of the Roughness

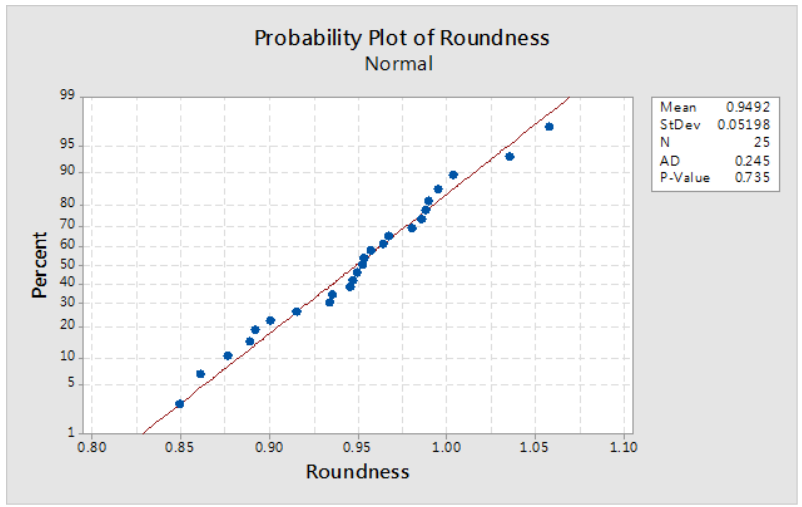

Figure 5. Normal probability plot of the Roundness

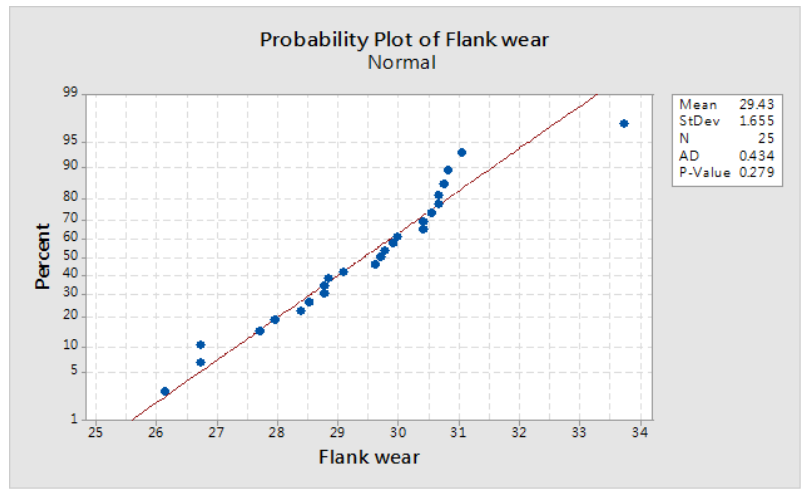

Figure 6. Normal probability plot of the Flank wear

\section{CONCLUSION}

This study examined Taguchi design and grey relational analysis to clarify the influence of various process parameters including the DC reactive co-sputter, aiming to obtain good surface roughness, precise roundness of the machined workpiece, and small flank wear of the cutting tool. The experimental results of the performance characteristics are introduced to calculate the $\mathrm{S} / \mathrm{N}$ ratio, grades, for predicting the optimal parameters using grey relational analysis. Using the optimal DC reactive co-sputter (coated tools) by applying the grey-based Taguchi method, the data show surface roughness decreased from $0.88 \mu \mathrm{m}$ to $0.73 \mu \mathrm{m}$, roundness decreased from $1.2 \mu \mathrm{m}$ to $0.95 \mu \mathrm{m}$, and flank wear decreased from $39.5 \mu \mathrm{m}$ to $28.3 \mu \mathrm{m}$. In the confirmation runs, it is clearly shown multiple performance characteristics can be improved using the grey-Taguchi method. Control charts tell us when special causes of variation are impacting our process. The Shewhart control chart technique has been widely applied in manufacturing industries because its chart is easy to plot, easy to interpret, and its control limits are easy to obtain. It is to demonstrate that the critical process and product characteristics are stable over time.

\section{ACKNOWLEDGEMENT}

Thanks to the support of the Department of Mechanical Engineering, Lunghwa University of Science \& Technology, so that the paper can be successfully completed.

\section{REFERENCES}

[1] Y.L. Su, T.H. Liu, C.T. Su, S.H. Yao, W.H. Kao, K.W. Cheng, J Mater Process Tech 171 (2006) 108.

[2] C. Subramanian, K.N. Strafford, Wear 165 (1993) 85.

[3] Z.C. Lin, C.Y. Ho, J Mater Process Tech 209 (2009) 303.

[4] M. Szutkowska, J Mater Process Tech 92 (1999) 355.

[5] C.Y. Hsu, Y.C. Lin, L.M. Kao, Mater Chem Phys 124 (2010) 330.

[6] G. Weise, A. Teresiak, I. Bächer, P. Markschläger, G. Kampschulte, Surf Coat Tech 76 (1995) 382.

[7] [P.J. Ross, Taguchi techniques for quality engineering: loss function, orthogonal experiments, parameter and tolerance design, McGrawHill Professional (1996).

[8] D.C. Montgomery, Design and Analysis of Experiments, Wiley, Singapore, 1991.

[9] N. Tosun, International Journal Advanced Manufacturing Technology 28 (2006) 450.

[10] [D.C. Montgomery, Introduction to Statistical Quality control, Wiley, Singapore, 1996. 
TABLE I. SETTING OF FACTORS AND LEVELS IN CO-SPUTTER DEPOSITION CONDITIONS TO FORM CRWN FILMS

\begin{tabular}{|c|c|c|c|c|}
\hline \multicolumn{2}{|c|}{ Substrate } & \multicolumn{3}{|c|}{ Tungsten carbide tool P30 } \\
\hline \multicolumn{2}{|l|}{ Gas } & \multicolumn{3}{|c|}{$\operatorname{Ar}(99.95 \%$ purity $), \mathrm{N} 2$ (99.95\% purity) } \\
\hline \multicolumn{2}{|c|}{ Base pressure } & \multicolumn{3}{|c|}{$5.0 \times 10-6$ torr } \\
\hline \multicolumn{2}{|c|}{ Substrate-to-target distance } & \multicolumn{3}{|l|}{$85 \mathrm{~mm}$} \\
\hline \multicolumn{2}{|c|}{ Substrate rotate speed } & \multicolumn{3}{|l|}{$10 \mathrm{rpm}$} \\
\hline \multicolumn{2}{|c|}{ Metal target } & \multicolumn{3}{|c|}{$\begin{array}{l}\text { W ( } 99.95 \% \text { purity), } \mathrm{Cr}(99.95 \% \text { purity }) \\
50.8 \mathrm{~mm} \text { diameter }\end{array}$} \\
\hline \multicolumn{2}{|c|}{ Substrate temperature $\left({ }^{\circ} \mathrm{C}\right)$} & \multicolumn{3}{|c|}{ room temperature } \\
\hline \multicolumn{2}{|c|}{ Deposition pressure } & \multicolumn{3}{|l|}{5 mtorr } \\
\hline \multicolumn{2}{|c|}{ Cr power } & \multicolumn{3}{|l|}{ DC } \\
\hline \multicolumn{2}{|c|}{ W power } & \multicolumn{3}{|c|}{ DC Pulse $30 \mathrm{KHz}$} \\
\hline Symbol & Control factor & Level 1 & Level 2 & Level 3 \\
\hline A & Cr power (Watt) & 80 & 100 & 120 \\
\hline $\mathrm{B}$ & $\begin{array}{l}\text { W power (Watt) } \\
N_{2} \\
\end{array}$ & 120 & 150 & 180 \\
\hline $\mathrm{C}$ & $\left(A r+N_{2}\right)(\%)$ & 2 & 6 & 10 \\
\hline $\mathrm{D}$ & Deposition time (min) & 1.5 & 3 & 4.5 \\
\hline
\end{tabular}

TABLE II. RESUlts OF ANOVA, FOR GREY RELATIONAL GRADES, FOR THE DEPOSITION OF CRWN THIN FILMS

\begin{tabular}{ccccc}
\hline Factor & Degrees of Freedom & Sum of Squares & Mean Square & $\begin{array}{c}\text { Contribution } \\
(\mathrm{P} \%)\end{array}$ \\
\hline A & 2 & 0.46 & 0.23 & 33.3 \\
B & 2 & 0.06 & 0.03 & 4.4 \\
C & 2 & 0.58 & 0.29 & 42.0 \\
D & 2 & 0.28 & 0.14 & 20.3 \\
Total & 8 & 1.38 & & 100.00 \\
\hline
\end{tabular}

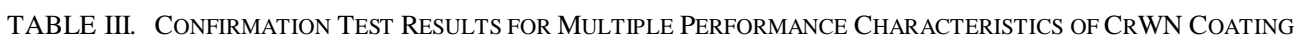

\begin{tabular}{cccc}
\hline Exp. & Roughness $(\mu \mathrm{m})$ & Roundness $(\mu \mathrm{m})$ & Flank wear $(\mu \mathrm{m})$ \\
\hline $\begin{array}{c}\text { Orthogonal array } \\
\text { A2B3C1D2 }\end{array}$ & 0.88 & 1.2 & 39.5 \\
\hline $\begin{array}{c}\text { Grey theory } \\
\text { Prediction design A2B3C1D3 }\end{array}$ & 0.73 & 0.95 & 28.3 \\
\hline Improvement Rate (\%) & 17.045 & 20.833 & 28.354 \\
\hline
\end{tabular}

